\title{
EL TESORO CELTIBÉRICO DE QUINTANA REDONDA (SORIA): NUEVOS DATOS Y MATERIALES
}

\author{
POR \\ ISABEL RODRÍGUEZ CASANOVA ${ }^{1}$ \\ Becaria, R.A.H.
}

\begin{abstract}
RESUMEN
Diversos documentos conservados en la Real Academia de la Historia y en la Real Academia de Bellas Artes de San Fernando han permitido reconstruir las circunstancias del hallazgo del conocido tesoro de Quintana Redonda, formado por más de mil denarios de bolśkan, un casco de bronce y dos recipientes de plata. Presentamos los dibujos de estos dos recipientes, un skyphos y un mastos realizados en el momento del descubrimiento y hasta ahora inéditos. La revisión del conjunto permite afirmar que pudo tratarse del tesoro de un militar romano y que su ocultación debe ser anterior a las guerras sertorianas.
\end{abstract}

\section{SUMMARY}

Several documents preserved in the Real Academia de la Historia and the Real Academia de Bellas Artes de San Fernando have allowed us to reconstruct the circumstances of the finding of the well-known hoard of Quintana Redonda, which consists of more than a thousand denarii of bolskan, a bronze helmet and two silver containers. We present the drawings of these two containers, a skyphos and a mastos, made at the time of the discovery, and unknown until now. By examining the set we can state that this could be a Roman soldier's treasure, and its hiding took place before the Sertorian wars.

PALABRAS CLAVE: Moneda celtibérica. Orfebrería. Circulación monetaria. Tesoros sertorianos.

KEY WORDS: Celtiberian coinage. Roman silver work. Monetary circulation. Sertorian coin-hoards.

Con motivo de la revisión de la documentación numismática conservada en la Real Academia de la Historia, han salido a la luz numerosas noticias, hasta ahora inéditas, sobre hallazgos monetales españoles².

\footnotetext{
${ }^{1}$ Este artículo ha sido redactado dentro del marco del proyecto de investigación post-doctoral «Origen de la colección de moneda hispánica de la Real Academia de la Historia», financiado por la Fundación Caja Madrid. Agradezco al Dr. D. Martín Almagro, Anticuario Perpetuo, su valiosa ayuda en la elaboración de este artículo, así como al Dr. D. Alberto Canto, de la Universidad Autónoma de Madrid, sus acertados consejos.

${ }^{2}$ La documentación del Gabinete Numario de la Real Academia de la Historia ha sido recientemente publicada por F. Martín, A. Cepas y A. Canto, Archivo del Gabinete Numario, Madrid, 2004.
}

La Academia de la Historia fue durante más de siglo y medio, esto es, desde su fundación en el siglo XVIII hasta finales del XIX, la principal institución encargada de la conservación del patrimonio arqueológico español. Especialmente en ese siglo XIX, las comisiones provinciales de antigüedades aportan información de primerísima mano acerca de los hallazgos que se efectúan en las áreas de su competencia, tal y como ha quedado reflejado en la publicación de los índices que de esta documentación se conserva en la Academia ${ }^{3}$. Una parte de estos descubrimientos arqueológicos pasa a enriquecer los fondos del Gabinete de Antigüedades de la Academia, especialmente hasta la creación del Museo Arqueológico Nacional y los museos provinciales.

El Gabinete Numario fue una de las partes más importantes del Gabinete de Antigüedades y desde su creación, hacia 1751 , se surtió tanto de aportaciones de los propios académicos, como de hallazgos monetarios que pasaban, en su totalidad o en una parte, a engrosar el pronto copioso monetario. La colección de moneda hispánica, en concreto, recientemente publicada, consta en la actualidad de más de 3700 piezas $^{4}$. Su procedencia es, desgraciadamente, desconocida en la mayoría de los casos, pero es fácilmente deducible que muchas de las monedas procede de tesoros, tal y como indican tanto las características físicas de las propias piezas — de cuños y conservación similares-, como la propia historia de la formación del monetario.

Existen varios hallazgos de moneda hispánica muy conocidos en la bibliografía numismática que se conservan, en su totalidad o en parte, en el Gabine-

\footnotetext{
${ }^{3}$ Los índices han sido publicados por Comunidades Autónomas por diversos autores, alcanzando casi veinticinco volúmenes: véase M. Almagro-Gorbea y J. Maier Allende (eds.), 250 años de Arqueología y Patrimonio. Documentación sobre Arqueología y Patrimonio Histórico de la Real Academia de la Historia. Estudio general e índices, Madrid, 2003.

${ }^{4}$ P. P. Ripollès y J. M. Abascal (eds.), Monedas hispánicas, Madrid, 2000.
} 


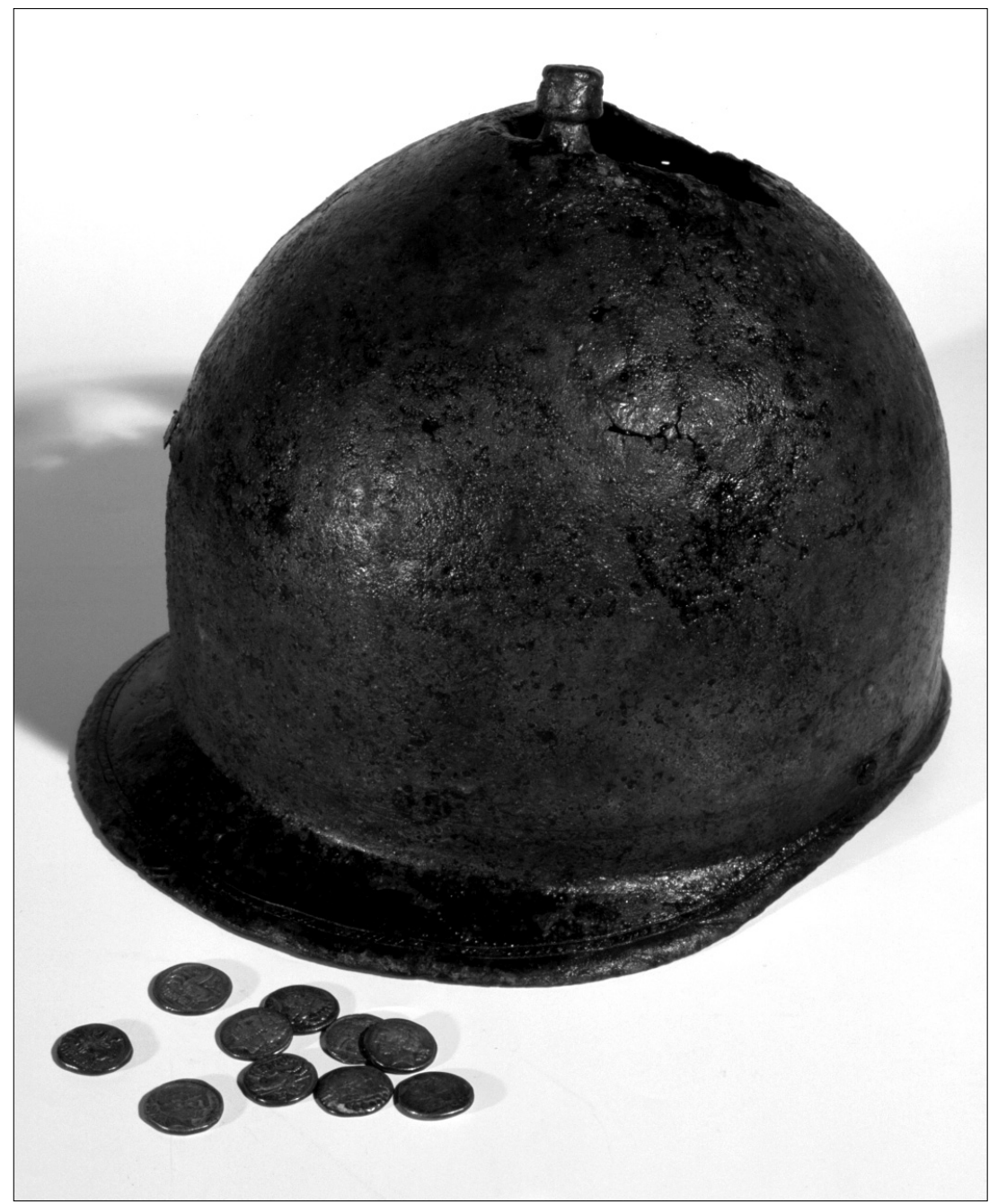

Fig. 1. Casco de bronce y denarios de bolśkan del tesoro de Quintana Redonda conservados en la Real Academia de la Historia (foto: Real Academia de la Historia).

te Numario. Entre ellos destaca el tesoro de Quintana Redonda (Soria), del que además se conserva en el Gabinete de Antigüedades el conocido casco de bronce $^{5}$ (Fig. 1).

Este tesoro no fue dado a conocer en la literatura científica hasta 1887 , fecha en la que se publica una noticia en el Boletín de la Real Academia de la Historia $^{6}$, en la que se dice que D. Mariano Álvarez,

${ }^{5}$ M. Almagro-Gorbea et al., Prehistoria. Antigüedades Españolas I. Real Academia de la Historia. Catálogo del Gabinete de Antigüedades, Madrid, 2004, $\mathrm{n}^{\circ}$ cat. 663, p. 328.

${ }^{6}$ S. A., «Noticias», BRAH, XII, p. 440. La matización de «literatura científica» viene al caso porque el descubrimiento del tesoro fue recogido en su momento por la prensa nacional, como queda constatado en un recorte conservado en el legajo correspondiente de la Academia de San Fernando, desde Ávila, ha adquirido un denario oscense de los encontrados en Quintana Redonda, veinte años atrás. El hallazgo, según el informante, estaba formado por dos pucheros llenos de monedas de plata, que habrían sido vendidas en Soria por mil pesetas.

Sin embargo, en el siguiente volumen de la publicación de la Academia, se recoge una rectificación en la que se explica que el tesoro estaba compuesto por 1.300 monedas contenidas en dos tazas de plata, cubiertas, a su vez, por un casco de bronce. Una

del diario La España, de Madrid, en su edición de tarde del viernes $1^{\circ}$ de mayo de 1863 . En la primera página, sección Interior, con encabezamiento «Soria, 27 de abril», se recoge información detallada del hallazgo, con descripción incluso de los tipos de las monedas. 
de las tazas, la que tenía asas, junto con las monedas que contenía, pasó al gobernador de Soria, mientras que la otra, el casco y el resto de las monedas llegaron a D. Eduardo Saavedra ${ }^{7}$. Como puede verse, ya desde ese temprano momento las noticias sobre el hallazgo y su composición eran confusas, incertidumbres que se han perpetuado en la bibliografía posterior.

Ya en el siglo xx, Horace Sandars vuelve a mencionar el tesoro en dos de sus publicaciones. En la primera de ellas ${ }^{8}$ lo cita en relación con el hallazgo de Santa Elena, dentro de una recopilación de tesoros españoles en los que han aparecido vasos, dando a entender que una de las tazas formaba parte de la colección Saavedra junto con setecientas monedas celtibéricas de Osca; menciona que tanto el vaso como las monedas se encontraron bajo un casco de bronce que se encontraba en el Museo de la Real Academia de la Historia y completaba el hallazgo un segundo vaso de plata, con la forma de los de Boscoreale, que se conservaba en la colección Diente. Se trata ésta de la mención más detallada que tenemos sobre la taza con asas, y la única que habla de su localización. En la segunda cita sobre el tesoro, Sandars ya se centra en el casco y resume las circunstancias del hallazgo diciendo que se encontró en Quintana Redonda en 1863 cubriendo dos tazas de plata llenas de monedas autónomas con la leyenda bolśkan ${ }^{9}$.

Autores posteriores hablan del tesoro con referencias cada vez menos precisas. B. Taracena resume que habían sido publicadas en el Boletín de la Academia, aunque fecha el hallazgo en 1868 , y habla de denarios ibéricos y romanos ${ }^{10}$. Gómez Moreno menciona únicamente 1.300 denarios de bolśkan ${ }^{11}$ y Mateu y Llopis, por su parte, dice que estaba compuesto por 2.500 monedas de bolśkan y que había aparecido hacia $1850^{12}$.

En los trabajos más recientes se continúa citan-

${ }^{7}$ S. A., «Noticias», BRAH, XIII, pp. 342-343. Es posible que de la segunda de estas noticias derive el error recogido en Almagro et al. (op. cit. nota 5) acerca de que la donación de Saavedra se produjo en 1888.

${ }^{8} \mathrm{H}$. Sandars, «Notes sur un dépôt de monnaies romaines découvert en Espagne (province de Jaen) en 1903», Revue Numismatique, 4, 1905, p. 398, $\mathrm{n}^{\circ} 7$.

${ }^{9} \mathrm{H}$. Sandars, The Weapons of the Iberians, Archaeologia, vol. LXIV, Oxford, 1913, p. 73.

${ }^{10}$ B. Taracena, Carta Arqueológica de España. Soria, Madrid, 1941, p. 137.

${ }^{11}$ M. Gómez Moreno, «Notas sobre numismática hispana», Miscelánea. Historia-Arte-Arqueología. Primera Serie: la Antigüedad, Madrid, 1949, p. 183.

${ }^{12} \mathrm{~F}$. Mateu y Llopis, «Los tesoros monetarios de la época sertoriana», publicado como apéndice de A. Schulten, Sertorio, Barcelona, 1949, p. 7; el autor cita la noticia del $B R A H$. do este tesoro entre aquellos a los que se atribuye una cronología sertoriana, aunque sin aportar nuevos datos. Así, entre otros, Raddatz ${ }^{13}$, Domínguez Arranz $^{14}$, Villaronga ${ }^{15}$, o García-Bellido y Blázquez ${ }^{16}$.

Como puede verse, las noticias son confusas, tanto en lo que se refiere a fecha del hallazgo como a la composición monetal del tesoro, pero pueden completarse en parte con la documentación conservada en la Academia de la Historia, al igual que se ha comprobado recientemente en otros hallazgos monetales ${ }^{17}$. Dicha documentación se distribuye en diversos legajos: el expediente de la Comisión Provincial de Antigüedades de Soria, con signatura CASO 9/ 7972/8; documentos del Gabinete Numario - GN 1863/08; 1864/6 y 1864-1865/1—; documentos de la Biblioteca como el legado de Fidel Fita - RAH 97582-, y las Actas de Sesiones de la Academia de aquellas fechas. Por otro lado, en el archivo de la Real Academia de Bellas Artes de San Fernando se conservan diversos papeles de la Comisión de Monumentos Históricos y Artísticos de Soria que complementan y amplían los datos que se conservan en su homóloga de la Historia y que iremos intercalando de forma cronológica para completar el relato de los avatares que sufrió el tesoro desde su descubrimiento.

Con fecha 26 de mayo de 1863, la Academia de San Fernando recibe una comunicación redactada por el Gobernador Civil de Soria, Eduardo Capelastegui, en su calidad de presidente de la Comisión de Monumentos Históricos y Artísticos, se conserva en el archivo de la Academia de San Fernando ${ }^{18}$ y en la que se recogen con todo detalle las circunstancias del

${ }^{13}$ K. Raddatz, Die Schatzfunde der iberischen Halbinsel, Berlin, 1969, pp. 242 ss., con una exhaustiva recopilación de la bibliografía anterior.

14 A. Domínguez Arranz, Medallas de la Antigüedad. Las acuñaciones ibéricas y romanas de Osca, Huesca, 1991, p. 193, n. $^{\circ} 42$.

${ }^{15}$ L. Villaronga, Tresors monetaris de la Península Ibèrica anteriors a August: repertori $i$ anàlisi, Barcelona, 1993, n. ${ }^{\circ} 109$. Únicamente habla de 1300 denarios de bolśkan.

${ }^{16} \mathrm{M}^{\mathrm{a}}$ P. García-Bellido y C. Blázquez, Diccionario de cecas y pueblos hispánicos, (en adelante citado DCPH) vol. I., p. 165, n. $^{\circ} 19$.

${ }^{17}$ I. Rodríguez Casanova, «La documentación del Gabinete de Antigüedades de la Real Academia de la Historia y su contribución a la numismática hispánica: el ejemplo de los «tesorillos» de Azuara», Revista General de Información y Documentación, vol. XVI.2, 2006, pp. 187-194; eadem, «Noticia de un tesorillo de denarios celtibéricos descubierto en Tarazona de Aragón (Zaragoza) en 1828», Nvmisma, 250, 2006; eadem, «Tesoros sertorianos: nuevas perspectivas desde datos antiguos», XIII CNN, Cádiz 2007 (e.p.); eadem, «Nuevos datos sobre el tesorillo celtibérico de Monte Lejarza-Larrabezúa» (en preparación).

${ }^{18}$ La documentación depositada en el Archivo de la Academia de San Fernando no posee más signatura que la general del legajo $(53-4 / 2)$, por lo que no puedo ofrecer referencia más concreta de los documentos. 
hallazgo: el lugar concreto fue un pago denominado «Las Quintanas», en el término municipal de Quintana Redonda, del distrito de Soria. El día 14 de abril, el dueño del terreno, José Hernández, se encontraba arando cuando la reja tropezó con un objeto que resultó ser el casco de bronce que contenía el tesoro, formado por las dos tazas de plata y mil veintiuna monedas. Tres días más tarde, cuando el gobernador, en compañía del vocal de la Comisión Provincial de Monumentos y del jefe de la sección de Fomento, llegó al lugar del descubrimiento, el tesoro había sido vendido al presbítero Tomás Celorio. Éste, y siempre según el relato de Capelastegui, consintió en vender para la Comisión de Monumentos una de las tazas, «la más notable», y cien de las monedas, entre ellas cuatro incusas. El resto del tesoro estaba reservado para el académico de la Historia, D. Domingo Saavaedra ${ }^{19}$.

Además de esta compra, Dionisio López de Cerain, vocal de la Comisión Provincial de Monumentos, pudo realizar los dibujos exactos de ambas tazas y un facsímil en cinz del casco. Dibujos que se conservan igualmente en el Archivo de la Academia de Bellas Artes de San Fernando y son el único testimonio que poseemos hoy en día de las tazas que formaban el tesoro.

Respecto de las monedas, se nos cuenta que presentan en anverso un busto sin morrión y la leyenda $* N$, y en reverso un guerrero a caballo, con lanza, al galope, y con la leyenda $* H \wedge M A N$. Todas eran iguales, y con buena conservación, aunque entre las mil veintiuna del total existían cuatro incusas. Adjunto al informe, Capelastegui envía a la Academia de San Fernando los dibujos del casco y de las tazas y diez de las monedas que había adquirido.

Esta institución recibe el donativo del Gobernador de Soria, como se constata en una carta que se le envía con fecha de 12 de junio de 1863, si bien decide que, al no poseer monetario propio, las monedas estarían mejor en la colección de la Academia de la Historia. En cuanto a las tazas, al considerarse objeto artístico de mérito, estaría muy interesada en comprar «la de asas» que poseía la Comisión Provincial de Soria.

Paralelamente, en ese mismo mes de junio, en la Real Academia de la Historia queda constancia del donativo de setecientas monedas de plata, junto con un vaso del mismo metal y un capacete de cobre encontrados en Quintana Redonda, por parte de Eduardo Saavedra y Moragas (quien, en ese momento, se encontraba excavando en las ruinas de la cercana $\mathrm{Nu}$ -

\footnotetext{
${ }^{19}$ Es evidente el error por Eduardo Saavedra.
}

mancia) como se recoge en un informe firmado por el Anticuario Antonio Delgado ${ }^{20}$ así como en el Acta de la Junta del 5 de junio de ese año.

Algunos días más tarde, el 19 del mismo mes, se recibe una nueva comunicación del hallazgo por parte de la Academia de Bellas Artes de San Fernando, quien obsequia a su institución hermana con las diez monedas de plata que formaban parte del tesoro y que obraban en su poder ${ }^{21}$. A propuesta de D. Antonio Delgado, se solicita a José Amador de los Ríos, académico de ambas instituciones, que interceda para que las tazas que figuran en el dibujo sean enviadas a Madrid para su examen y depósito ${ }^{22}$.

Sin embargo, meses después, ya en 1864, llega así la comunicación del robo de la parte del tesoro que permanecía en poder de la Comisión Provincial de Monumentos Históricos y Artísticos, esto es, la taza con asas, noventa monedas y el facsímil del $\operatorname{casco}^{23}$. Este último será encontrado, algunos meses más tarde, en las dependencias particulares del gobernador $^{24}$.

A finales de dicho año la Academia de la Historia recibe el regalo de tres piezas del tesoro de Quintana Redonda de manos de su correspondiente en Almería, D. Francisco Javier de León Bendicho, quien, a su vez, las había conseguido de quien era gobernador de la provincia de Soria en el momento del hallazgo, el ya mencionado Eduardo Capelastegui, que había sido trasladado a esa provincia andaluza ${ }^{25}$.

Así pues, la Academia habría recibido 713 piezas de las cerca de 1.100 que componían el hallazgo: las setecientas donadas por Saavedra, las diez que aporta la Real Academia de San Fernando y las tres que regala Francisco Javier de León Bendicho, lo que supone casi dos terceras partes del total, además del casco y una de las tazas de plata. Las tres donaciones aparecen recogidas en otro documento del Ga-

\footnotetext{
${ }^{20}$ GN 1864/6(2).

${ }^{21}$ Se trata del documento CASO/9/7972/08(1). También se conserva copia en el archivo de la Academia de San Fernando.

${ }^{22}$ Acta de 19/6/1863; CASO/9/7972/08(3): es copia del original que se conserva en el Archivo de la Academia de San Fernando. Hablar de tazas en plural parece un error, puesto que una de ellas ya la tendría la Academia de la Historia. Es posible que en este momento se produjera un conflicto de intereses entre ambas instituciones, pues las dos estaban interesadas en adquirir para sus colecciones respectivas la «taza con asas», de ahí que la intermediación se solicitara a Amador de los Ríos, como académico de ambas.

${ }^{23} \mathrm{CASO} / 9 / 7972 / 08(5)$.

${ }^{24}$ CASO/9/7972/08(6).

${ }^{25}$ Véase el informe de la donación en GN 1864-1865/1(2). En este documento se recogen de nuevo los datos ya conocidos sobre el hallazgo y su composición.
} 


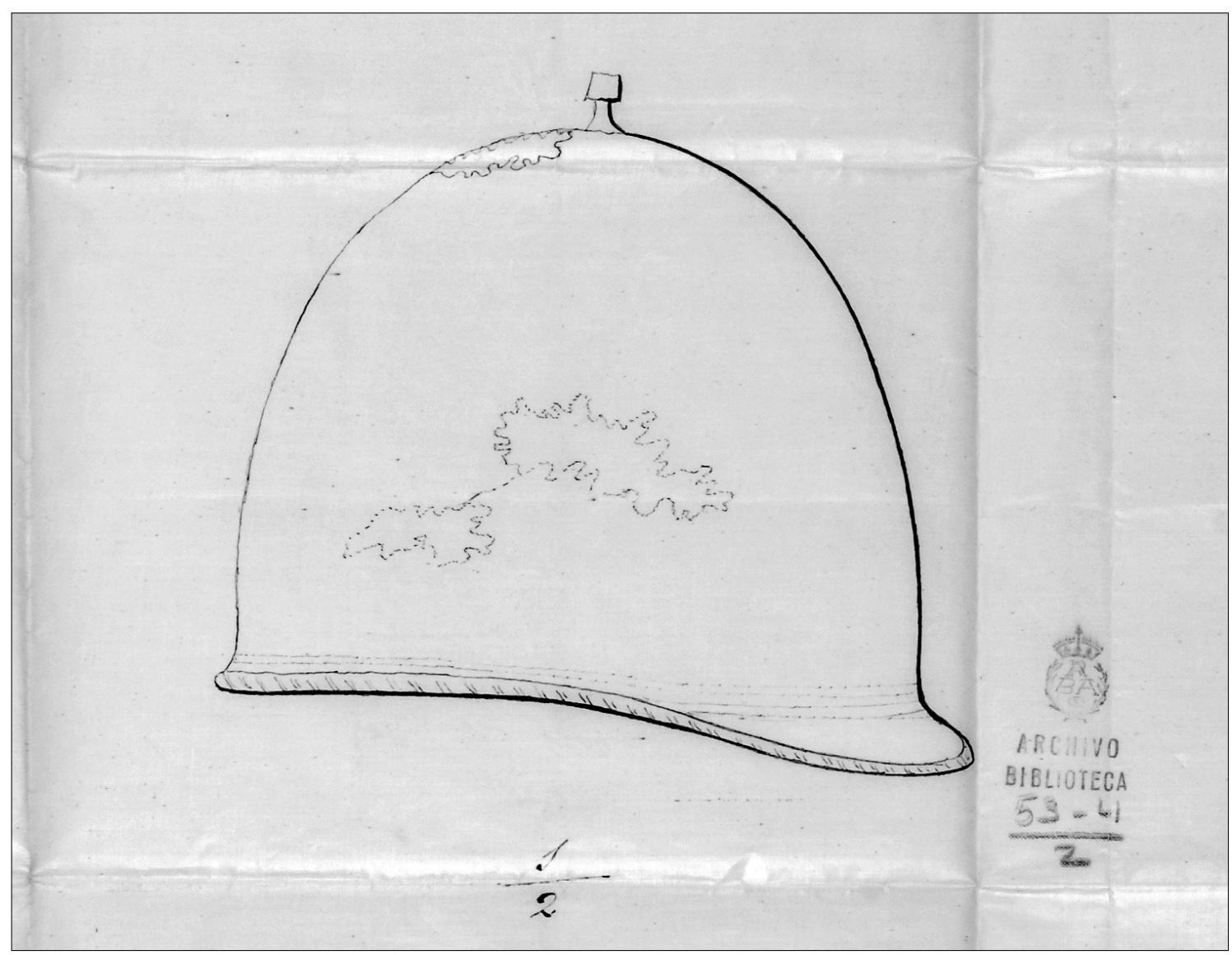

Fig. 2. Dibujo del casco de bronce del tesoro de Quintana Redonda realizado por Dionisio López de Cerain en el momento de su descubrimiento (foto: Archivo Real Academia de Bellas Artes de San Fernando).

binete Numario — GN 1865/6 — titulado «Donativos de monedas y objetos de Antigüedades», donde se resumen los ingresos de piezas entre los años 1863 y 1865. Sin embargo, cuando este documento es reproducido en las Noticias de las Actas... publicadas en 1868, la mención al donativo de Saavedra de las piezas de Quintana Redonda ha desaparecido ${ }^{26}$.

\section{COMPOSICIÓN DEL TESORO}

Después de esta revisión documental, podemos decir con seguridad que el tesoro de Quintana Redonda estaba formado por un casco de bronce, dos tazas de plata y un número indeterminado de monedas

${ }^{26}$ P. Sabau, Noticias de las actas de la Real Academia de la Historia leída en Junta Pública de 7 de junio e 1868, [Apéndice] Núm. II. Donativos de monedas y objetos de antigüedad, pp. 13-21. Madrid, 1868. que oscilaba entre las 1.021 y las 1.100 . Veamos ahora con detalle cada uno de estos elementos.

El casco de bronce, como se ha dicho, se conserva en el Gabinete de Antigüedades de la Real Academia desde 1863, fecha de la donación, casi inmediata al hallazgo, que realizó el académico Saavedra. (Fig. $2)^{27}$. Se considera de tipo Montefortino, atribuyéndosele una fecha que oscila entre el siglo in y el primer tercio del primero. Presenta una sencilla decoración en la parte inferior, que no se aprecia con detalle en el dibujo original, en el que únicamente se esbozan unas líneas de puntos y trazos oblicuos, por lo que es posible que en un primer momento, quizás antes

${ }^{27}$ Sobre el casco puede consultarse una completa descripción, así como dimensiones, análisis metalográfico, bibliografía, etc. en Almagro et al. (op. cit. nota 5, pp. 328 ss., $\mathrm{n}^{\circ}$ cat. 663) aunque hay que realizar algunas matizaciones en lo que se refiere a las circunstancias del ingreso de la pieza en la Academia, que fue en 1863 y no en 1888 como en ella se indica. 
de la limpieza de la pieza, no fueran bien visibles estos motivos decorativos.

\section{LAS TAZAS}

Gracias a los dibujos conservados en el Archivo de la Real Academia de Bellas Artes de San Fernando, y que reproducimos en este trabajo, es posible conocer por primera vez las dos tazas que formaban parte del tesoro de Quintana Redonda. Estos dibujos, como ya se ha dicho, fueron realizados por Dionisio
López de Cerain, entonces vocal de la Comisión de Monumentos Históricos y Artísticos de Soria. Están realizados a tinta sobre papel vegetal, a tamaño natural y con anotación del peso de las piezas.

La primera de ellas (Fig. 3), que se venía describiendo como «taza con asas», al parecer se encontraba en poder de la Comisión de Monumentos de Soria, y habría sido depositada en las dependencias del Gobierno Civil de la provincia hasta que fue robada de allí en 1864 , tal y como se recoge en la documentación vista anteriormente. En la actualidad se encuentra en paradero desconocido.



Fig. 3. Dibujo de la «taza con asas» que formaba parte del tesoro de Quintana Redonda, realizado por Dionisio López de Cerain en el momento de su descubrimiento (foto: Archivo Real Academia de Bellas Artes de San Fernando). 
Se trata de un skyphos cuyas medidas son $18,9 \mathrm{~cm}$ de longitud máxima (de extremo a extremo de las asas), $12,5 \mathrm{~cm}$ de diámetro en la boca y $6,5 \mathrm{~cm}$ de diámetro en la base, con $7 \mathrm{~cm}$ de altura total. Podría describirse como una copa carenada, con borde ligeramente exvasado en la parte superior y un pequeño pie anular moldurado. Presenta dos asas aplicadas formadas por tres elementos: la parte superior es una pieza de forma trapezoidal, plana, que sirve de apoyo para los pulgares y que continúa el plano horizontal del borde del recipiente; le sigue el asa propiamente dicha, de forma anular, y por último un remate, que, a juzgar por el dibujo, podría recordar una forma vegetal, que serviría como refuerzo, y se une a la taza a unos dos tercios de su altura total.

La vista superior del recipiente nos permite apreciar dos pequeños rebordes en la boca del skyphos, así como la forma de las asas. En el interior de la copa se han marcado con punteado tres círculos concéntricos que cabe interpretar como el diámetro de la base y el pie, mejor que como decoración interna. El peso del recipiente era de 10 onzas y 5 adarmes, lo que se traduce por, aproximadamente, $296 \mathrm{~g}$.

El skyphos es una de las formas más comunes del argentum potorium de finales de la República, aunque se hace más habitual a comienzos del Imperio, si bien en esa época es habitual que aparezca cubierta de decoración aplicada o repujada ${ }^{28}$. Nos encontramos sin duda ante una forma de tradición helenística, desarrollada a partir de un prototipo cerámico griego $^{29}$, que resulta muy poco común en la Península Ibérica, donde sólo se había constatado hasta el momento en otro tesoro descubierto en 1930 en Poio (Paradela de Guiâes, Portugal), en el que se recuperaron dos recipientes similares ${ }^{30}$. Al igual que en Quintana Redonda, en Poio aparecieron diversos objetos de servicio de mesa — dos skyphoi, una jarra y un cuenco o plato- en compañía de monedas de plata, en este caso al parecer todas romanas, aunque no pudieron ser estudiadas en su totalidad ${ }^{31}$. Tradicionalmente se ha venido incluyendo este tesoro entre los de cronología sertoriana por ser la más moderna de las conservadas una pieza de la emisión

\footnotetext{
${ }^{28}$ Raddatz (op. cit. nota 13, pp. 96 ss.); VV. AA., Tresors d'orfevrerie gallo-romains [Catálogo de exposición], Paris, 1989, p. 65.

${ }^{29}$ D. E. Strong, Greek and Roman Gold and Silver plate, London-New-York, 1966, p. 133; Raddatz (op. cit. nota 13, pp. 96 ss.) con bibliografía, etc.

${ }^{30}$ Raddatz (op. cit. nota 13, pp. 96 y s. y 281).

${ }^{31}$ F. R. Cortez, 1952-3, «O Tesouro monetário do lugar do Poio (Paradela de Guiâes). Contributo numismático para o estudo da romanizaçâo da Regiâo do Douro», Nummus, 1, pp. 6-37.
}

de C. Postumius del año 74 a.C. (RRC 394/1a) $)^{32}$ y si bien una reciente revisión de las monedas propone retrasar su fecha hasta el 49-48 a. C. ${ }^{33}$, a falta de datos más seguros se puede seguir considerando este tesoro como de época sertoriana ${ }^{34}$.

El skyphos de Quintana Redonda es muy similar, a juzgar por el dibujo, al más pequeño de los aparecidos en Poio, en cuanto a forma se refiere, especialmente si nos fijamos en las asas, aunque el ejemplar soriano presentaría la carena mucho más marcada. En cuanto al tamaño, estaría entre los dos de Poio, tanto en altura como en diámetro.

Este recipiente puede encuadrarse dentro del tipo de copas o vasos de Boscoreale ${ }^{35}$, tal y como apuntó correctamente Sandars, aunque con algunas puntualizaciones. El tesoro de Boscoreale, descubierto en 1895 en una villa rústica cercana a Pompeya, está formado por diferentes objetos de plata, entre los que destaca el servicio de mesa ${ }^{36}$. Sus más conocidas copas pertenecen a época ya imperial y presentan una decoración muy elaborada, con aplicaciones o repujada, característica habitual en los skyphoi de esa etapa, si bien algunos ejemplares de decoración más sencilla parecen ser anteriores, siendo estos últimos los más próximos a los ejemplares hispanos.

La forma también ha sido documentada en hallazgos de Francia, Italia o Dinamarca, en diversos contextos. Entre los descubrimientos más recientes se encuentra el hallazgo de Thorey (cerca de St. Germaine-du-Plain, Saône et-Loire), que se produjo en 1986 durante el transcurso de unos trabajos de dra-

${ }^{32} \mathrm{RRCH}=\mathrm{M}$. Crawford, Roman Republican Coin Hoards, London, 1969, p. 104, n ${ }^{\circ} 305$; con otra periodización, pero en fechas similares: Villaronga (op. cit. nota 15, p. 54, $\mathrm{n}^{\circ}$ 122); Raddatz (op. cit. nota 13, págs. 96 y 281), siguiendo a Russel Cortez (op. cit. nota 31) habla del 64 a. C. como fecha de la moneda más moderna, puesto que siguen la cronología de Babelon.

${ }^{33}$ R. M. S. Centeno, Circulaçâo monetária no noroste de Hispânia até 192, Anexos Nummus, no 1, Porto, 1987, pp. 73 ss.: corrige el número de denarios encontrados hasta 913 y añade cuatro argollas pequeñas lisas y un bolo de plata de casi tres kilos y medio de peso. En su catalogación figuran tres nuevos denarios procedentes de una colección privada, uno de los cuales pertenece al tipo RRC 443/1, emitido por Julio César en Italia en el 49-48 a. C., pieza que desentona de todo el conjunto anterior.

${ }^{34}$ L. Amela, «La circulación monetaria romano-republicana durante la guerra sertoriana según las ocultaciones de la época (82-72 a. C.)», Gaceta Numismática, 97-98, 1990, p. 22; J. Ruivo, «O conflicto sertoriano no ocidente hispânico: o testemunho dos tesouros monetários», AEspA, 70, 1997, p. 93; etc.

${ }^{35}$ Sandars (op. cit. nota 8, p. 398).

${ }^{36}$ Una publicación reciente de este tesoro de Boscoreale en F. Baratte, Le trésor d'orfevrerie romaine de Boscoreale, Paris, 1986. 


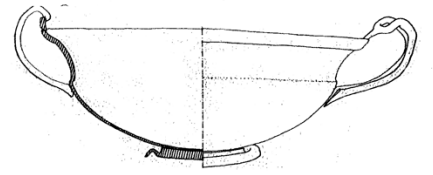

a

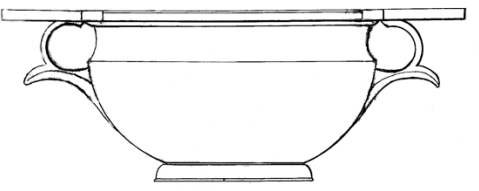

d

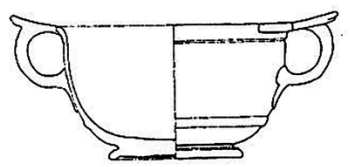

g

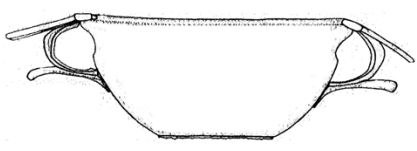

b

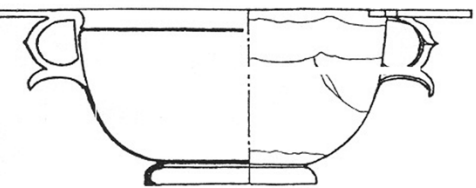

e

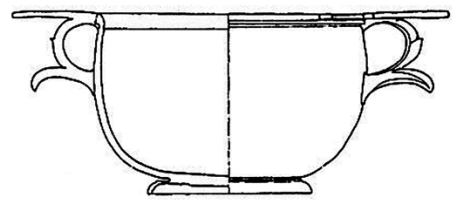

$\mathrm{h}$

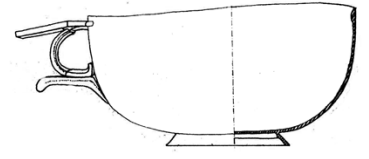

c

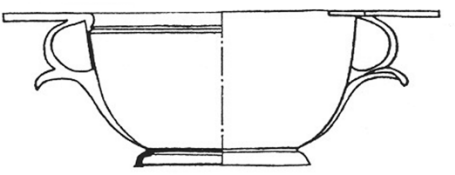

f

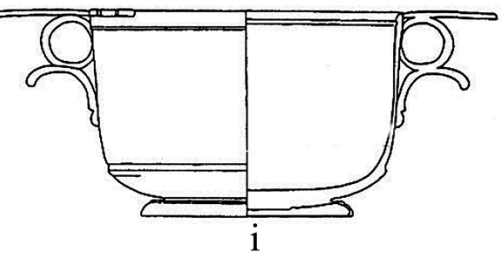

Fig. 4. Algunos skyphoi republicanos y alto-imperiales: a, b y c: Palmi; d: Quintana Redonda; e y f: Poio; g, h, i: Boscoreale.

gado del río Saona ${ }^{37}$. Se trata de un conjunto formado por dos copas y un skyphos, todos ellos de plata, considerados como una importación italiana. La interpretación propuesta para este hallazgo, al que se atribuye una cronología de primera mitad del siglo I a.C., es que las piezas podrían haber viajado en un barco cuando se produjo su pérdida accidental. Se atribuye al conjunto una cronología de primera mitad del siglo I a. C. ${ }^{38}$. Si nos fijamos en el skyphos, de cuerpo ligeramente exvasado, veremos que presenta unas asas muy similares a las vistas en el de Quintana Redonda, con el que coincide también en medidas.

También procedente de la Galia es el tesoro de Berthouville, del que forma parte la «copa de los centauros», un skyphos, aunque a veces se conozca como kantharos, con decoración en relieve. El conjunto estaba dedicado en su templo al Mercurio Canetonense y de su carácter votivo dan fe los nombres de los dedicantes, entre ellos quien dedica esta copa, de procedencia itálica ${ }^{39}$.

En el conjunto descubierto en 1929 en Palmi (Reggio Calabria, Italia) se recuperaron tres tazas que

${ }^{37}$ VV. AA., Tresors d'orfevrerie gallo-romains [Catálogo de exposición], Paris, 1989, p. 64.

${ }^{38}$ VV. AA. (ibm.).

${ }^{39} \mathrm{~F}$. Baratte, «Remarques préliminaires à un inventaire de la vaiselle d'argent rouvée en Gaule», en N. Duval y F. Baratte (eds.), Argenterie romaine et Byzantine. Actes de la Table Ronde. Paris, 11-13 octobre 1983, Paris, 1988, p. 90; VV. AA. (op. cit. nota 37, pp. 79 ss.). recuerdan en gran medida a las de Quintana Redon$\mathrm{da}^{40}$. Las número 3 y 4 presentan una pequeña carena en el tercio superior del vaso, aunque, a diferencia de los ejemplares hispanos, la forma del recipiente es ligeramente exvasada, y las asas son totalmente distintas; en cambio la número 5 presenta asas similares en tres partes y cuerpo hemiesférico. La taza número 4 presenta además en su interior una inscripción cuyas características epigráficas permiten datarla en la primera mitad del siglo II a. C. ${ }^{41}$, cronología anterior a la fecha de ocultamiento del tesoro, que se habría producido en el primer cuarto del siglo I a. C. ${ }^{42}$.

Para concluir el listado de paralelos entre los skyphoi europeos más conocidos, citaré el procedente de Giubiasco, en el cantón de Tesino, en Suiza, recuperado en una necrópolis tardía de La Tène ${ }^{43} \mathrm{y}$, aunque ya de época imperial, los skyphoi de Hoby

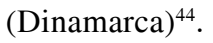

${ }^{40}$ P. G. Guzzo, «Argenteria da Palmi in ripostiglio del I sec. A. C.», Atti e memorie della Società Magna Grecia, XVIII-XX, 1977-1979, pp. 193-209.

${ }^{41}$ Guzzo (op. cit. nota 40, p. 206).

${ }^{42}$ Guzzo (op. cit. nota 40, pp. 207 ss.). La fecha vendría dada por una lucerna de barniz negro (n $\left.{ }^{\circ} 8\right)$ con decoración radial.

${ }^{43}$ H. Gabelmann, «Der silberne Skyphos aus Giubiasco», Helvetia Archaeologica, 13, 1982, pp. 9-32.

${ }^{44}$ E. Künzl, «Germanien und Rom», en VV. AA. Kaiser Augustus und die verlorene Republik, Berlin, 1988, pp. 569 ss.; nr. 396-397. 
Desde el punto de vista de la tipología, de todos estos skyphoi europeos, los de Quintana Redonda, Poio y Palmi 3 y 4 son los únicos que presentan el cuerpo carenado, mientras que en el resto las paredes del vaso tienden a la forma cilíndrica o ligeramente ovoide (Fig. 4). Sería posible pensar que los ejemplares hispanos ilustran un paso intermedio entre las piezas carenadas, exvasadas y sin decoración de Palmi, fechadas en la primera mitad del siglo II, y los ejemplares de Thorey, de primera mitad del I a.C., que ya han perdido la carena presentando un perfil hemiesférico, evolución estilística que culminaría en época augustea y altoimperial con las elaboradas piezas de Hoby o Boscoreale.

Por lo que respecta al lugar de fabricación y su funcionalidad, parece aceptado, por lo visto en los estudios realizados sobre los ejemplares europeos, que se trataría de objetos de importación ${ }^{45}$. Su función como regalos diplomáticos parece evidente en el caso de las copas de Hoby (Dinamarca), firmadas además por un artesano de nombre griego ${ }^{46}$.

La segunda de las tazas de Quintana Redonda que, al parecer, habría sido donada por Eduardo Saavedra a la Real Academia de la Historia, y cuyo paradero actual se ignora, es un recipiente hemiesférico, tipo cuenco (Fig. 5). Sus medidas eran 13,4 cm de diámetro en la boca y $7 \mathrm{~cm}$ de altura. Parece tener un pequeño reborde en la parte superior de unos $6 \mathrm{~mm}$ en el que podría tener una decoración punteada. $\mathrm{Su}$ peso era de 7 onzas y 13 adarmes, lo que puede traducirse por, aproximadamente, $224 \mathrm{~g}$.

Este tipo de cuenco es muy sencillo y habitual en la orfebrería hispana, aunque también aparece en otras zonas de Europa como los Balcanes ${ }^{47}$. Tipológicamente, suele englobarse en un mismo apartado con otro tipo de cuencos de forma cónica, con el nombre genérico de mastos, y se utilizarían como recipiente de bebida ${ }^{48}$. Recientemente se ha documentado este tipo también en Francia ${ }^{49}$.

\footnotetext{
${ }^{45}$ Baratte (op. cit. nota 39 , p. 87 ).

${ }^{46}$ VV. AA. (op. cit. nota 37, p. 63 )

${ }^{47}$ Strong (op. cit. nota 29, p. 108); su habitual presencia en los tesoros hispanos ya la hemos visto constatada por Sandars (op. cit. nota 8, pp. 397 s.) y en estudios posteriores, por ejemplo por ejemplo, A. Blanco Freijeiro, «Plata oretana de «La Alameda» (Santisteban del Puerto, Jaén)», AEspA, vol. $\mathrm{XL}, \mathrm{n}^{\circ} 115-116,1967$, pp. 92-99, quien recoge la existencia de cuencos similares en los hallazgos de Torre de Juan Abad (Ciudad Real), Almadenes de Pozoblanco, Molino de Marrubial y La Grajuela (Córdoba), o Perotito y Los Villares en la provincia de Jaén.

${ }^{48}$ Strong (ibm.).

${ }^{49}$ Véase por ejemplo, el cuenco procedente de Eyres-Moncube (Landes): VV. AA. (op. cit. nota 37, p. 61, no 4, p. 55).
}

Si cotejamos las medidas del recipiente de Quintana Redonda con los promedios de medidas y pesos elaborados por Raddatz en su apartado dedicado a esta tipología, encontramos que es ligeramente más pequeño del tamaño medio calculado que rondaba los $15 \mathrm{~cm}$ de diámetro ${ }^{50}$, quedándose en $13,4 \mathrm{~cm}$. El peso, tal y como lo hemos calculado por las indicaciones del dibujo, tampoco llega al de la libra romana que pesarían algunos ejemplares de Andalucía.

Por lo que se refiere a piezas similares documentadas, ya en el inventario elaborado por el mismo autor se recogían veintisiete ejemplares ${ }^{51}$, a las que hoy es posible añadir algunas más como los del tesoro de Chiclana de Segura (Jaén), donde aparecieron, entre otros objetos de plata, cuatro de estos recipientes $^{52}$. La práctica totalidad de los hallazgos de estas piezas de platería se concentra en la zona sur de la Península Ibérica, asociada a tesoros de la zona de Sierra Morena y Valle del Guadalquivir ${ }^{53}$. Algunos de ellos pueden fecharse con cierta seguridad gracias a las monedas romanas que también formaban parte de su composición, como es el caso de los de Molino de Marrubial, Almadenes de Pozoblanco, Chiclana de Segura, etc. ${ }^{54}$. De este modo se engloban en un periodo cronológico cercano al año 100 a. C. ${ }^{55}$, ilustrando un horizonte de inestabilidad para el cual

\footnotetext{
${ }^{50}$ Raddatz (op. cit. nota 13, p. 86).

${ }^{51}$ Raddatz (op. cit. nota 13, p. 86), procedentes de los hallazgos de Alcornocal (Fuenteobejuna, Córdoba), Azuel (Córdoba), Molino de Marrubial (Córdoba), Almadenes de Pozoblanco (Córdoba), Castellar de Santiago (Ciudad Real), Castillo de las Guardas (Sevilla), Fuensanta de Martos (Jaén), Mengíbar (Jaén), Santiesteban del Puerto (Jaén), Torre de Juan Abad (Ciudad Real), Cástulo (Jaén), Los Villares (Jaén), Padrad (Proença-a-Nova, Castelo Branco).

${ }^{52}$ L. Avellá Delgado y P. Rodríguez Rus, «Un tesoro de plata procedente de Chiclana de Segura», Boletín del Instituto de Estudios Giennenses, XXXII, n 126, 1986, pp. 23-58.

${ }^{53}$ En la recopilación de Raddatz (op. cit. nota 13, p. 89) únicamente se recoge el hallazgo portugués de Padrad fuera de esta región.

${ }^{54}$ Una reciente revisión de estos tesoros en T. Volk, «The composition, distribution, and formation of Roman Republican coin-hoards from s. Hispania, c. 100 BC», en R.M. S. Centeno; Ma P. García-Bellido y G. Mora (coords.). Rutas, ciudades y moneda en Hispania. II Encuentro Peninsular Numismática y Arqueología, Porto, 1998, Anejos AEspA, XX, 1999, pp. 349-364. La relación entre tesoros y cuencos hemiesféricos aparece recogida en la tabla B y en la p. 352. También F. Chaves, Los tesoros en el Sur de Hispania. Conjunto de denarios y objetos de plata durante los siglos II y I a. C., Sevilla, 1996. Los objetos de plata han sido estudiados, en ese mismo volumen, por $\mathrm{M}^{\mathrm{a}} \mathrm{L}$. de la Bandera, «Objetos de plata que acompañan a las tesaurizaciones», pp. 609-702.

${ }^{55}$ Hay que precisar que Villaronga (op . cit. nota 15, p. 55 , $\mathrm{n}^{\circ}$ 128), fecha el tesoro de Almadenes de Pozoblanco en relación con las guerras pompeyanas, retrasando su cronología hasta mediados del siglo I a. C., y C. Blázquez («Tesorillos de moneda republicana en la península ibérica. Addenda a
} Roman Republican Coin Hoards», Acta Numismàtica, 17-18, 


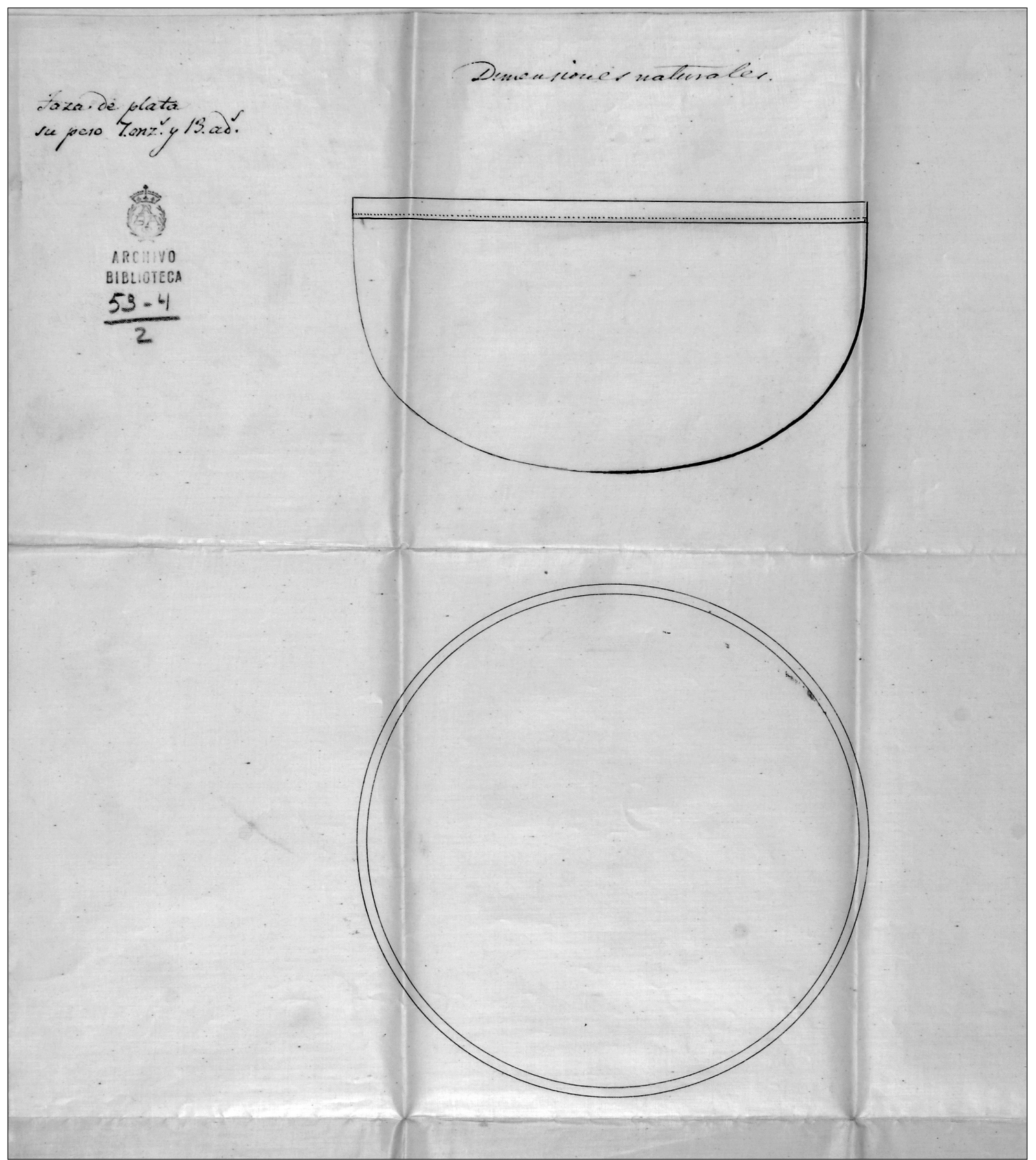

Fig. 5. Dibujo del cuenco hemiesférico que formaba parte del tesoro de Quintana Redonda, realizado por Dionisio López de Cerain en el momento de su descubrimiento (foto: Archivo Real Academia de Bellas Artes de San Fernando).

1988 , p. 141, $\left.\mathrm{n}^{\circ} 119\right)$ lo da como de cronología incierta, si bien autores posteriores lo vuelven a incluir en este horizonte del año 100: A. Arévalo, «La circulación monetaria en las minas de Sierra Morena: El distrito de Córdoba», Numisma, 237, 1996, pp. 66 ss.; T. Volk, «Nuevos datos sobre el tesoro del Cerro del Peñón («Los Almadenes en Pozoblanco, 1925-1926»)», Numisma, 237, 1996, pp. 83 ss., etc. no se ha encontrado aún una explicación cierta ${ }^{56}$. Según Volk, la aparición de piezas de argentería (vasos y coladores) sólo se produce en las tesauriza-

${ }^{56}$ Volk (op. cit. nota 54, p. 362); también Villaronga (op. cit. nota 15 , pp. 78 ss.) o García-Bellido y Blázquez (op. cit. nota 16 , p. 130). 
ciones andaluzas de esta época y no se repite en los hallazgos de época posterior, de modo que, aún en el caso de que faltaran las monedas, sería posible fechar los tesoros con estas piezas de orfebrería a finales del siglo II y principios del I a. C. ${ }^{57}$.

\section{LAS MONEDAS}

Como se constata en la documentación conservada, las monedas recuperadas en el hallazgo de Quintana Redonda superaban las mil piezas, hablándose en un primer momento de mil veintiuna y después de mil cien. De ellas, al parecer la Real Academia de la Historia habría recibido un total de setecientas trece, de tres donaciones diferentes: las setecientas donadas por Eduardo Saavedra, las diez recibidas de la Real Academia de San Fernando y finalmente, tres monedas donadas por su correspondiente Francisco Javier de León Bendicho.

De todas estas piezas sólo se ha conseguido identificar diez. Se trata en concreto de las monedas de bolśkan con los números de catálogo n. ${ }^{\circ}$ 1237-1244, 1250 y $1251^{58}$. Las primeras ocho monedas corresponden al tipo $\mathrm{CNH} 211.2^{59}$, que se caracteriza por presentar en anverso una cabeza masculina barbada con collar, a derecha, y detrás los signos ibéricos bo.n., y en reverso jinete lancero a derecha, debajo, sobre línea, bolśkan. Las dos últimas (n. ${ }^{\circ}$ cat. 1250 y 1251) presentan como tipo de reverso el mismo de anverso incuso, catalogándose como $\mathrm{CNH}$ 211.3. Este número coincide con las diez piezas donadas por la Real Academia de San Fernando, que además se conservaron en su sobre original hasta la reciente ordenación de la colección de moneda hispánica.

De la donación de Bendicho quedó constancia en varios documentos. En el primero, redactado por el propio correspondiente, aunque detalla la procedencia de las monedas, no proporciona ningún dato físico de las piezas, salvo que son de plata. Sin embargo, se conserva entre los papeles del Gabinete Numario el informe realizado por D. Antonio Delgado sobre esta donación. Se trata de un documento titulado «Monedas $\mathrm{q}^{\mathrm{e}}$ han pasado al monetario de la

\footnotetext{
${ }^{57}$ Volk (op. cit. nota 54, p. 352).

${ }^{58}$ Catalogadas por A. Domínguez en Ripollès y Abascal (op. cit. nota 4, pp. 185 ss.). También M. Almagro Gorbea, «Casco de bronce y denarios celtibéricos del Tesoro de Quintana Redonda», en M. Almagro (ed.), Tesoros de la Real Academia de la Historia, Madrid, 2001, no 54 y 55, p. 230. En esta publicación, sin embargo, se atribuye a Saavedra la donación de estas diez piezas.

${ }^{59} \mathrm{CNH}=\mathrm{L}$. Villaronga, Corpus Nummum Hispanie ante Augusti Aetatem, Madrid, 1994.
}

Academia en $1865 »$, en el cual se recoge un listado más completo de esta donación ${ }^{60}$. Aunque en este caso ya no se cita la procedencia de las monedas, puede deducirse que las dos monedas de bolśkan que describe Delgado en su lista podrían proceder de Quintana Redonda. De una de ellas, además, nos dice que presenta el reverso incuso, particularidad que sabemos se daba en algunas monedas del tesoro que habían sido adquiridas por Capelastegui ${ }^{61}$.

Parece evidente que, si la composición del tesoro era, tal y como nos dicen los primeros informes, denarios de bolśkan exclusivamente y, por tanto, las piezas ingresadas en el Monetario de la Academia de la Historia lo serían, éstas se han perdido, como también habrían desaparecido en este siglo y medio el cuenco hemiesférico que fue donado junto con ellas. Quizás la explicación más sencilla sea que la donación de Saavedra de las setecientas monedas y el cuenco de plata nunca llegó a materializarse, a pesar de que la hemos encontrado constatada en varios documentos, lo que explicaría que en la primera publicación del tesoro en el Boletín de la Real Academia de la Historia de 1888 se hubiera perdido toda memoria de estos materiales ${ }^{62}$.

La emisión a la que corresponden las monedas del tesoro identificadas, se considera la segunda y se fecha, según autores, en la segunda mitad del siglo II a.C. ${ }^{63}$ o desde segunda mitad de este siglo II hasta

${ }^{60} \mathrm{GN} 1866 / 1$. Aunque parezca existir un desfase de fechas entre la donación y el documento, no hay tal, pues la donación se produce en diciembre de 1864. Además, el cotejo de ambos documentos demuestra que nos encontramos ante las mismas piezas, a pesar de que en el segundo no se mencionen las procedencias. Lo mismo sucede en la publicación de esta donación: P. Sabau, Noticia de las actas de la Real Academia de la Historia leída en Junta Pública de 7 de junio de 1868. Núm. II. Donativos de monedas y objetos de antigüedad, Madrid, 1868, pp. 14 ss.

${ }^{61}$ Ver supra, documentación. En este documento, sin embargo, sólo se habla de dos denarios de bolśkan.

${ }^{62}$ Todos los esfuerzos dedicados a encontrar algún otro rastro de esta donación en la Academia de la Historia, aparte de los documentos citados, han resultado infructuosos. He llegado a plantearme la hipótesis de que el hallazgo no estuviera compuesto únicamente por piezas de bolśkan sino que entraran en su composición denarios de otras cecas celtibéricas y romanas. Me aferraba a indicios como la donación de León Bendicho, la noticia de Taracena (op. cit. nota 10, p. 137) hablando de denarios celtibéricos y romanos, o en el detalle de que Delgado siempre habla de moneda de plata y no de moneda céltica como sucedía en los documentos enviados desde Soria. Esta «línea de investigación» ha resultado equivocada: Taracena posiblemente interpretó erróneamente el término «denario común oscense» utilizado en la primera noticia del tesoro, pero la prueba definitiva es que en el Monetario de la Academia no se constata ningún aumento considerable de la colección de moneda hispánica ni de la romana tras la redacción del inventario de Delgado en 1862 (GN 1862/02; GN 1862/06 y GN 1862/07).

${ }^{63} \mathrm{CNH}$ (p. 211); DCPH (II, p. 307). 
el primer cuarto del $\mathrm{I}^{64}$. La presencia de piezas de esta emisión en tesoros de diferentes fechas certifica su dilatada cronología: se encuentra bien representada en los tesoros del sur peninsular cercanos al año 100, que hemos visto anteriormente, como Carissa, Marrubial, Almadenes de Pozoblanco, Torres, Granada II, o Salvacañete; también aparece en hallazgos relacionados con el horizonte sertoriano - Maluenda, Nájera y Salamanca-, pero perdura hasta poder encontrarse en hallazgos tan tardíos como Arrabalde (cuya ocultación se fecha en relación con las guerras cántabras), y el de Villar del Álamo, de época ya augustea ${ }^{65}$.

Sobre estos hallazgos, y sin pretender realizar un exhaustivo estudio sobre la cronología de las monedas de bolśkan, hay que hacer algunas precisiones. En primer lugar, el tipo que estamos estudiando aparece con mucha más profusión en los hallazgos pertenecientes al que denominaremos «horizonte del año 100». Estos tesoros se encuentran bastante bien datados por aparecer en ellos denarios romanos ${ }^{66}$.

Los tesoros «sertorianos» en los que se encuentra representada esta emisión de bolśkan son muchos menos: Maluenda, Nájera y Salamanca. Sobre su cronología hay que matizar que sólo del primero podemos asegurar una fecha sertoriana por entrar en su composición denarios romanos, el más moderno de los cuales se fecha en el 77 a.C. ${ }^{67}$. Los tesoros de Nájera $^{68}$ y Salamanca ${ }^{69}$ compuestos únicamente por moneda ibérica, no pueden ser datados sino por paralelismos y deducciones. En ambos, la presencia de denarios de bolśkan es muy residual, con un solo ejemplar en cada uno ${ }^{70}$. Por último, la presencia de denarios de bolśkan en fechas tan tardías como las guerras cántabras, y aún más, época augustea, no indica sino una circulación residual en zonas periféricas (Arrabalde).

\footnotetext{
${ }^{64}$ Domínguez (en Ripollès y Abascal (eds.) op. cit. nota 4, p. 182).

65 Sigo en este apartado los datos proporcionados en DCPH (nota 16, I, Apéndice C: Tesoros, y vol. II, p. 307).

${ }^{66}$ Véase, especialmente Chaves (op. cit. nota 54), además de las consideraciones y la bibliografía correspondiente citada en el apartado dedicado a los recipientes hemiesféricos.

${ }^{67}$ Blázquez (op. cit. nota 55, p. $126, \mathrm{n}^{\circ} 65$ ), con toda la bibliografía anterior.

${ }^{68}$ J. A. Ocharan Larrondo, «El tesorillo de Nájera y los denarios de śekobirikes», en $\mathrm{M}^{\mathrm{a}}$ P. García-Bellido y R.M. S Centeno (eds.), I Encuentro Peninsular Numismática y Arqueología. La moneda hispánica. Ciudad y territorio, Anejos AEspA, XIV, Madrid, 1995, pp. 215-218.

${ }^{69} \mathrm{M}^{\mathrm{a}} \mathrm{P}$. García-Bellido, «Tesorillo salmantino de Denarios Ibéricos», Zephyrus, XXV, 1974, pp. 379-395.

${ }^{70}$ En el caso del de Nájera, de entre 219 denarios ibéricos, sólo uno es de bolśkan y del tipo $\mathrm{CNH}$ 211.6, aunque muy posiblemente este tipo pertenezca a la misma emisión que el CNH 211.2.
}

De otra parte, si nos fijamos en los tesoros recuperados en zonas próximas a la de Quintana Redonda y que son conocidos con un mayor grado de certidumbre, y a los que igualmente se supone una fecha de ocultación sertoriana, no deja de ser chocante una composición única de moneda de bolśkan. Un rápido repaso por estos hallazgos de la Meseta y el Valle del Ebro, nos indica una presencia bastante residual de esta ceca en detrimento de las cuatro más habituales: śekobirikes, tuŕiaśu, aŕekórata y arsaos ${ }^{71}$. Aún variando los porcentajes, estos cuatro talleres forman el grueso de la práctica totalidad de los tesoros conocidos en toda esta región. Un ejemplo de ello es el tesoro de Palenzuela, que se fecha por el último de los denarios romanos conservados, post. 74 a. C., si bien presenta un porcentaje relativamente alto de piezas de bolśkan - 5,71\% de las más de dos mil seiscientas que lo componían-, éstas pertenecen a una emisión que es considerada posterior a la recuperada en Quintana Redonda ${ }^{72}$.

Los hallazgos documentados en la provincia de Soria no aportan apenas datos a la solución del problema. El de Retortillo de Soria, cercano geográficamente a Quintana Redonda, se conoce únicamente por noticias muy imprecisas: publicado por Gómez Moreno y recogido por Taracena, el primer autor en ningún momento menciona que el tesoro se encontrara dentro de una taza de plata ${ }^{73}$. Igualmente imprecisa es la noticia del tesoro de Pozalmuro, transmitida por Eduardo Saavedra, con los únicos datos de que se trataba de una olla repleta de monedas iguales hallada en 1835, de las que consigue recuperar un denario de tuŕiasu que dona a la Real Academia de la Historia ${ }^{74}$.

Entre los tesoros documentados en la cercana región del Valle del Ebro, el hallazgo de Maluenda,

${ }^{71}$ Un cuadro con la presencia de estas cecas en muchos de los tesoros que estamos analizando, aunque en relación con el taller de śekobirikes puede consultarse, en $\mathrm{M}^{\mathrm{a}} \mathrm{P}$. GarcíaBellido, «Sobre la localización de Segobrix y las monedas del yacimiento de Clunia», AEspA, 67, 1994, pp. 253 s.

${ }^{72}$ Se trataría de la cuarta emisión (DCPH II, pág. 308; tipos CNH 212.12-13).

${ }^{73}$ M. Gómez Moreno, «Notas sobre numismática hispana», $A n$. $C A B$ y A., t. II, 1934, p. 186; edición emendata en Miscelánea, Historia-Arte-Arqueología. Primera Serie: la Antigüedad, Madrid, 1949, p. 183; la mención de Taracena (op. cit. nota 10, p. 143) es anterior a este segundo trabajo.

${ }^{44}$ E. Saavedra, Descripción de la Vía Romana entre Uxama y Augustobriga, Madrid, 1861, p. 48. Se trata de la moneda $\mathrm{n}^{\circ}$ 1502 del catálogo. P. Madoz, Diccionario geográfico-estadístico-histórico de España y sus posesiones de ultramar. Soria, Madrid 1845-1850 (reed. Valladolid, 1984), p. 190, recoge estas mismas noticias con más detalle sobre las monedas, que no eran todas iguales. Taracena (op. cit. nota 10, p. 137) también recoge esta noticia, ampliada con menciones de otros autores, pero igualmente con datos poco claros. 
posiblemente el mismo que el de Aluenda ${ }^{75}$, es el que presenta una composición más parecida a la de Quintana Redonda, en tanto que en ambos la única moneda ibérica representada era la de bolśkan (a excepción de una pieza de śekobirikes en Maluenda). Este hallazgo, sin embargo, y a la luz de los estudios realizados sobre circulación monetaria en la Tarraconensis, resulta extraño para la zona, especialmente por la presencia de moneda romana ${ }^{76}$, por lo que es posible que no se formara en la región sino que llegara ya en bloque como producto de algún pago ${ }^{77}$.

Así pues, si bien es cierto que esta muestra de monedas no alcanza ni siquiera el $1 \%$ del total del hallazgo, resulta curioso que todas pertenezcan a la misma emisión, mayoritariamente reconocida como de las más antiguas de la ceca, con una cronología que, a juzgar por su representación porcentual en los tesoros, estaría bastante más cercana al cambio de siglo que a las guerras sertorianas.

\section{CONCLUSIÓN}

Tras la revisión de toda la documentación presentada pueden darse por seguros algunos datos sobre el tesoro de Quintana Redonda. El hallazgo se produjo en 1863 y estaba compuesto por un número de monedas de plata cercano a las mil (mil veintiuna en el primer informe), un casco de bronce de tipo Montefortino y dos recipientes de plata: un cuenco hemiesférico y un skyphos, elementos característicos del servicio de mesa.

A pesar de la exhaustiva revisión documental llevada a cabo para este trabajo, ha sido imposible reconstruir con seguridad las circunstancias que ocasionaron la pérdida del tesoro, sin embargo sí cabe anotar que en los años siguientes al hallazgo se producen una serie de factores que pudieron influir en esta pérdida. Dentro de la Academia de la Historia, Antonio Delgado deja el cargo de Anticuario en 1865, cuando se jubila, y habrá que esperar a septiembre de 1867 para que sea nombrado Aureliano Fernández Guerra, quien no toma posesión hasta diciembre. Es posible que Delgado, entonces, no tuviera tiempo material de catalogar todas las piezas ni de dejar constancia de su procedencia, algo que sí sucede con

${ }^{75}$ L. Villaronga, «Notas a un hallazgo de denarios en Maluenda (Zaragoza)», Ampurias, XXVI-XXVII, 1964-1965, pp. 165-179.; J. A. Hernández Vera, «Aportaciones al conocimiento del Tesoro de Maluenda», Numisma, 165-167, 1980, pp. 119-128; Blázquez (1987-88, p. 126, nº 65).

${ }^{76}$ P. P. Ripollès, La circulación monetaria en la Tarraconense mediterránea, Valencia, 1982, pp. 305 ss.

${ }^{77}$ Chaves (op. cit. nota 54, p. 50). la mayoría de las donaciones que se realizan durante el ejercicio de su cargo, incluida la de las diez monedas de este mismo hallazgo de Quintana Redonda que había donado la Real Academia de Bellas Artes de San Fernando ${ }^{78}$.

A este periodo de transición entre la jubilación de Delgado y la toma de posesión del siguiente anticuario se unen la complicada situación política que desemboca en la revolución de 1868 y que tiene su reflejo en el funcionamiento académico ${ }^{79}$. Prueba de ello es el paréntesis que se produce en las publicaciones institucionales, por ejemplo en las Noticias ${ }^{80}$. Es posible pensar que la conjunción de estos elementos pudo suponer, si no la pérdida de los propios materiales, desde luego sí su olvido.

Por lo que se refiere a los datos aportados por los nuevos materiales recuperados, me atrevo a decir que ninguno de los elementos que componían el tesoro de Quintana Redonda permite, por sí mismo, certificar la cronología sertoriana del hallazgo. El casco, característico del ejército romano, debió pertenecer a un militar, posiblemente a un oficial, y, por su tipología, puede datarse entre inicios del siglo II y mediados del i a. C. ${ }^{81}$. La tipología del cuenco hemiesférico, muy similar a la de los documentados en tantos tesoros del sur peninsular, nos remitiría a una cronología cercana al año 100 que avalan los denarios recuperados en esos mismos hallazgos. Por otra parte, las monedas que han podido ser catalogadas, aunque sean en un porcentaje inferior al $1 \%$, pertenecen todas a un mismo tipo y a una emisión

\footnotetext{
${ }^{78}$ Hay que anotar que la fecha de descubrimiento del tesoro impidió a Delgado incluirlo en su obra Nuevo método de clasificación de las medallas autónomas de España, Sevilla, 1871 y 1876 , que, había sido redactada con anterioridad y donde sí se menciona, en alguna nota a pie de página, la donación de Saavedra de las moneda halladas en la vía entre Uxama-Augustobriga, de 1861, (Delgado, 1876, III, p. 14, n. al p.) con la apostilla de «recientes investigaciones».

${ }^{79}$ M. Almagro ( $« \mathrm{El}$ Archivo de la Comisión de Antigüedades: una visión de conjunto», en M. Almagro-Gorbea y J. Maier (eds.), 50 años de Arqueología y Patrimonio. Documentación sobre Arqueología y Patrimonio histórico de la Real Academia de la Historia. Estudio general $e$ índices, Madrid, 2003, p. 214) habla de crisis reflejada en el volumen de documentos recopilados en los años del sexenio revolucionario.

${ }^{80}$ Las Noticias de las actas de la Real Academia de la Historia..., redactadas por Pedro Sabau, y que habían tenido hasta entonces una periodicidad anual o bianual, no se editan entre 1862 y 1868 . Estas noticias habían dejado de publicarse en las Memorias de la Real Academia de la Historia desde 1852 y aún habrá que esperar hasta 1877 para que comience a editarse el Boletín de la Real Academia de la Historia.

${ }^{81}$ Almagro (op. cit. nota 5, p. 330) afirma que, aunque las monedas apuntan a cronología sertoriana, «el casco pudiera ser algo anterior».
} 
que parece tener su auge en esas mismas fechas de mediados del siglo II hasta principios del I, tal y como acreditan igualmente esos mismos tesoros. Solamente la presencia de un skyphos de plata, cuyo único paralelo en la Península se encuentra en el tesoro portugués de Poio, podría asegurar la cronología sertoriana del hallazgo. Sin embargo, el hecho de que contemos con un único paralelo, plantea la duda de si la relación podría ser a la inversa y los skyphoi de Poio fueran las piezas más antiguas del hallazgo, no contemporáneas de las monedas. Recordemos que las tazas de Palmi, también carenadas, se datan en la primera mitad del siglo iI a. C.

No podemos dejar de lado que este tesoro de Quintana Redonda difiere radicalmente en su composición de todo lo visto hasta ahora en los hallazgos monetales de la Meseta Norte y del Valle del Ebro: monedas de un único taller y recipientes de servicio de mesa, un tipo de objetos poco habitual en los tesoros celtibéricos, donde lo corriente es que aparezcan joyas o fragmentos de ellas, en compañía de las monedas (casos de Padilla, Palencia, Roa, etc. ${ }^{82}$. Tampoco se conoce vajilla de plata en otros contextos arqueológicos de la zona, por lo que la explicación más plausible es que nos encontramos ante un objeto de importación.

Llegados a este punto, creo que puede plantearse la hipótesis de que este tesoro fuera propiedad de un militar romano que lo ocultó bajo su casco, y que su fecha podría ser anterior a las guerras sertorianas. Anteriormente se había planteado la posibilidad de que el poseedor del tesoro fuera un soldado celtibérico ${ }^{83}$, sin embargo la presencia exclusiva de moneda celtibérica no indica necesariamente que el dueño tuviera que serlo, puesto que el papel de las cecas hispánicas en el cobro de impuestos y de pagos relacionados con las tropas con anterioridad a ser utilizadas por el bando sertoriano, y en relación de igualdad con la moneda oficial romana, está siendo tenido en cuenta cada vez más por los investigadores $^{84}$. Parece perfectamente posible que un oficial romano pudiera estar en posesión de esta clase de numerario, así como de las dos piezas de orfebrería, sin duda alguna objetos de importación. Sin embargo, tal y como sucede en muchos otros aspectos de la arqueología, nos movemos en el terreno de

\footnotetext{
${ }^{82}$ Hay que esperar a los tesoros mucho más tardíos de Arrabalde para documentar piezas de orfebrería en los tesoros de la meseta.

${ }^{83}$ Como apunta Almagro (op. cit. nota 5).

${ }^{84}$ Véase, por ejemplo, Chaves (op. cit. nota 54, p. 520) o F. Beltrán, «De nuevo sobre el origen y función del «denario ibérico», La moneda en la societat ibèrica. II Curs d'Història monetària d'Hispània, Barcelona, 1998, pp. 109 ss.
}

la hipótesis. En lo referido a las ocultaciones monetales, insistimos en aplicar determinados modelos, intentando insertar cada tesoro en un horizonte de inestabilidad, cuando ni siquiera conocemos, como en este caso, su composición completa, y quizás nunca alcancemos a discernir las verdaderas causas que llevaron a la ocultación de muchos de los tesoros que han llegado a nuestros días.

\section{BIBLIOGRAFÍA}

Almagro-Gorbea, M., 2001, «Casco de bronce y denarios celtibéricos del Tesoro de Quintana Redonda», en M. Almagro Gorbea (ed.), Tesoros de la Real Academia de la Historia, Madrid.

- 2003, «El Archivo de la Comisión de Antigüedades: una visión de conjunto», en M. AlmagroGorbea y J. Maier (eds.), 250 años de Arqueología y Patrimonio. Documentación sobre Arqueología y Patrimonio histórico de la Real Academia de la Historia. Estudio general e índices, Madrid, pp. 209-224.

Almagro-Gorbea, M., y Maier Allende, J., (eds.), 2003, 250 años de Arqueología y Patrimonio. Documentación sobre Arqueología y Patrimonio Histórico de la Real Academia de la Historia. Estudio general e índices, Madrid.

Almagro-Gorbea, M., et al., 2004, Prehistoria. Catálogo del Gabinete de Antigüedades. Antigüedades Españolas I. Real Academia de la Historia, Madrid.

AmelA, L., 1990, «La circulación monetaria romanorepublicana durante la guerra sertoriana según las ocultaciones de la época (82-72 a. C.)», Gaceta Numismática, 97-98, pp. 19-30.

Arévalo, A., 1996, «La circulación monetaria en las minas de Sierra Morena: El distrito de Córdoba», Numisma, 237, pp. 51-82.

Avellá Delgado, L., y Rodríguez Rus, P., 1986, «Un tesoro de plata procedente de Chiclana de Segura», Boletín del Instituto de Estudios Giennenses, vol. XXXII, n 126 , pp. 23-55.

Bandera, M. ${ }^{a}$ L. de la, 1996, «Objetos de plata que acompañan a las tesaurizaciones», en F. Chaves, Los tesoros en el Sur de Hispania. Conjunto de denarios y objetos de plata durante los siglos II y I a. C., Sevilla, pp. 609-702.

BARATTE, F., 1986, Le trésor d'orfevrerie romaine de Boscoreale, Paris.

- 1988, «Remarques préliminaires à un inventaire de la vaiselle d'argent rouvée en Gaule», en N. Duval y F. Baratte (eds.), Argenterie romaine et 
Byzantine. Actes de la Table Ronde. Paris, 11-13 octobre 1983, Paris, pp. 85-95.

Beltrán, F., 1998, «De nuevo sobre el origen y función del «denario ibérico», La moneda en la societat ibèrica. II Curs d'Història monetària d'Hispània, Barcelona, pp. 101-117.

Blanco Freijeiro, A., 1967, «Plata oretana de «La Alameda» (Santisteban del Puerto, Jaén)», AEspA, vol. XL, no 115-116, pp. 92-99.

Blázquez, C., 1988, «Tesorillos de moneda republicana en la península ibérica. Addenda a Roman Republican Coin Hoards», Acta Numismàtica, 1718, pp. 105-142.

Crawford, M., 1969, Roman Republican Coin Hoards, London.

- 1974, Roman Republican Coinage, Cambridge.

Centeno, R. M. S., 1987, Circulaçâo monetária no noroeste de Hispânia até 192, Anexos Nummus, $\mathrm{n}^{\circ} 1$, Porto.

Cortez, F. R., 1952-3, «O Tesouro monetário do lugar do Poio (Paradela de Guiâes). Contributo numismático para o estudo da romanizaçâo da Regiâo do Douro», Nummus, 1, pp. 6-37.

Delgado, A., 1871 y 1876, Nuevo método de clasificación de las medallas autónomas de España, Sevilla.

Domínguez Arranz, A., 1991, Medallas de la Antigüedad. Las acuñaciones ibéricas y romanas de Osca, Huesca.

García-Bellido, M. ${ }^{\mathrm{a}}$ P., 1974, «Tesorillo salmantino de Denarios Ibéricos», Zephyrus, XXV, pp. 379-395.

- 1994, «Sobre la localización de Segobrix y las monedas del yacimiento de Clunia», AEspA, 67, pp. 245-259.

García-Bellido, M. ${ }^{a}$ P., y Blázquez, C., 2001, Diccionario de pueblos y cecas de la Hispania antigua, Madrid.

Gómez Moreno, M., 1934, «Notas sobre numismática hispana», $A n$. $C A B$ y A., t. II, pp. 173-191.

- 1949, «Notas sobre numismática hispana», Miscelánea. Historia-Arte-Arqueología. Primera Serie: la Antigüedad, Madrid, pp. 175-186.

Guzzo, P. G., 1977-1979, «Argenteria da Palmi in ripostiglio del I sec. A. C.», Atti e memorie della Società Magna Grecia, XVIII-XX, pp. 193-209.

Hernández Vera, J. A., 1980, «Aportaciones al conocimiento del Tesoro de Maluenda», Numisma, 165-167, pp. 119-128.

Madoz, P., 1845-1850 (reed. Valladolid, 1984), Diccionario geográfico-estadístico-histórico de España y sus posesiones de ultramar, Soria, Madrid.

Martín, F.; Cepas, A., y Canto, A., 2004, Archivo del Gabinete Numario. Catálogo e índices, Madrid.

Mateu y Llopis, F., 1949, «Los tesoros monetarios de la época sertoriana», en A. Schulten, Sertorio, Barcelona.

Ocharan Larrondo, J. A., 1995, «El tesorillo de Nájera y los denarios de śekobiŕikes», en M. ${ }^{a}$ P. García-Bellido y R. M. S. Centeno (eds.), I Encuentro Peninsular Numismática y Arqueología. La moneda hispánica. Ciudad y territorio, Anejos AEspA, XIV, Madrid, pp. 215-218.

KüNZL, E., 1988, «Germanien und Rom», en Kaiser Augustus und die verlorene Republik, Berlin, pp. 529-605.

Pozo, S. F., 2005, «La vajilla metálica de la provincia Baetica. III. La Argentería romana», Antiqvitas, 17, pp. 33-56.

RadDATZ, K., 1969, Die Schatzfunde der iberischen Halbinsel, Berlin,.

Ripollès, P. P., y Abascal, J. M., (eds.), 2000, Monedas hispánicas. Real Academia de la Historia. Catálogo del Gabinete de Antigüedades, Madrid.

Rodríguez Casanova, I., 2006, «La documentación del Gabinete de Antigüedades de la Real Academia de la Historia y su contribución a la numismática hispánica: el ejemplo de los «tesorillos» de Azuara», Revista General de Información y Documentación, vol. XVI.2, pp. 187-194.

- 2006, «Noticia de un tesorillo de denarios celtibéricos descubierto en Tarazona de Aragón ( $\mathrm{Za}$ ragoza) en 1828», Nvmisma, 250.

- (e.p.) «Tesoros sertorianos: nuevas perspectivas desde datos antiguos», XIII CNN, Cádiz 2007.

- (en preparación), «Nuevos datos sobre el tesorillo prerromano de Monte Lejarza-Larrabezúa».

Ruivo, J., 1997, «O conflicto sertoriano no ocidente hispânico: o testemunho dos tesouros monetários», AEspA, 70, pp. 91-100.

SaAvedra, E., 1861, Descripción de la Vía Romana entre Uxama y Augustobriga, Madrid.

SABAU, P., 1868, Noticias de las actas de la Real Academia de la Historia leída en Junta Pública de 7 de junio e 1868, [Apéndice] Núm. II. Donativos de monedas y objetos de antigüedad, pp. 1321. Madrid.

SANDARs, H., 1905, «Notes sur un dépôt de monnaies romaines découvert en Espagne (province de Jaen) en 1903», Revue Numismatique, 4, pp. 396405 .

- 1913, The Weapons of the Iberians, Archaeologia, vol. LXIV, Oxford,

S. A., 1888, «Noticias», BRAH, XII, pág. 440. 
S. A., 1888, «Noticias», BRAH, XIII, pp. 342-343. Strong, D. E., 1966, Greek and Roman Gold and Silver plate, London-New-York.

TARACEnA, B., 1941, Carta arqueológica de España. Soria, Madrid.

Villaronga, L., 1964-1965, «Notas a un hallazgo de denarios en Maluenda (Zaragoza)», Ampurias, XXVI-XXVII, pp. 165-179.

- 1993, Tresors monetaris de la Península Ibèrica anteriors a August: Repertori i Análisi, Barcelona.

- 1994, Corpus nvmmvm Hispaniae ante Avgvsti aetatem, Madrid.

Volk, T., 1996, «Nuevos datos sobre el tesoro del
Cerro del Peñón ("Los Almadenes en Pozoblanco”, 1925-1926)», Numisma, pp. 83-131.

- 1999, «The composition, distribution, and formation of Roman Republican coin-hoards from s. Hispania, c. 100 BC», en R. M. S. Centeno; M. ${ }^{a}$ P. García-Bellido y G. Mora (coords.). Rutas, ciudades y moneda en Hispania. II Encuentro Peninsular Numismática y Arqueología, Porto, 1998, Anejos AEspA, XX, pp. 349-364.

VV.AA., 1989, Tresors d'orfevrerie gallo-romains [Catálogo de exposición], Paris.

Recibido el 25-06-07. Aceptado el 24-03-08. 